\title{
One Step Clean-Up Method Combined with Single Accelerated Solvent Extraction for Analysis of Polycyclic Aromatic Hydrocarbons and Phenols in Creosote-Treated Woods by Gas Chromatography-Mass Spectrometry ${ }^{\dagger}$
}

\author{
Byung Rye Go, Hong Seok Choi, Hai Dong Kim, and Joohoon Kim* \\ Department of Chemistry and Research Institute for Basic Sciences, College of Sciences, Kyung Hee University, \\ Seoul130-701, Korea.*E-mail: jkim94@khu.ac.kr \\ Received July 2, 2010, Accepted July 26, 2010
}

\begin{abstract}
Key Words: Creosote-treated wood, Polycyclic aromatic hydrocarbons, Phenols, Ion exchange resin, Gas chromatography-mass spectrometry
\end{abstract}

Creosote is a thick oily liquid that is obtained by fractional distillation of crude coal tars. ${ }^{1}$ It is widely used as a wood preservative and a water-proofing agent for outdoor wood structures such as railway ties, poles for transport of electricity, and fences for children's playgrounds. ${ }^{2}$ A primary concern regarding the wide use of creosote is the long-term release of a variety of toxic constituents present within creosote-treated wood into the environment. ${ }^{3-5}$ The constituents of creosote include polycyclic aromatic hydrocarbons (PAHs, $\sim 85 \%)$, phenols ( $\sim 10 \%)$, and N-, S-, O-heterocyclic compounds $(\sim 5 \%))^{6}$ Among the constituents, PAHs and phenols are considered as important pollutants because of their toxicity and high contents in creosote. For example, the US Environment Protection Agency (EPA) has defined 16 PAHs and 11 phenols, which are found in high quantities in creosote, as priority pollutants. ${ }^{7-8}$ The main constituents of creosote has been also reported as being carcinogenic to humans. ${ }^{9-10}$ Therefore, it is important to analyze PAHs and phenols in creosote-treated wood for minimizing the risk of human health and environmental contamination.

Due to the environmental and health risk concerns, analysis of PAHs and phenols in creosote-treated wood has been performed using classical extraction and clean-up methods. ${ }^{11-12}$ They often employ separate extraction and clean-up steps for each group of PAHs and phenols prior to chromatographic analysis. Therefore, they require laborious and time-consuming multi-step procedures, which cause use of large amounts of organic solvents and loss of PAHs and phenols during the analysis. It is, thus, highly desirable to develop a rapid but reliable analytical procedure for the identification and quantification of the problematic constituents, i.e. PAHs and phenols, in creosote-treated wood.

Here, we report an efficient one step clean-up method combined with single accelerated solvent extraction (ASE) for the quantitative analysis of PAHs and phenols in creosote-treated woods by gas chromatography-mass spectrometry (GC-MS). The approach involves a single extraction step of both PAHs and phenols utilizing ASE technique and subsequent one step clean-up through ion exchange liquid chromatography for separation of PAHs and phenols in the extract. The extracted PAHs and phenols were separated into basic/neutral and acidic frac-

${ }^{\dagger}$ This paper is dedicated to Professor Hasuck Kim for his outstanding contribution to electrochemistry and analytical chemistry. tions, respectively. Each fraction was then quantified by GC-MS for the determination of 16 PAHs and 9 phenols (Table 1) in creosote-treated wood. We compared the proposed one step clean-up method with a conventional clean up method, i.e., EPA method 3650 . The EPA method 3650 is an acid/base partition clean-up method to separate acids (phenolic compounds) from basic/neutral compounds (PAHs) using $\mathrm{pH}$ adjustment. ${ }^{13}$ In addition, the developed approach was validated in terms of method detection limit (MDL), and was applied to determine trace amounts of PAHs and phenols in creosote-treated commercial wood samples.

The proposed method was tested by spiking noncreosotetreated wood samples with the standards of 16 PAHs and 11 phenols (Table 1$)$. The wood samples $(0.5 \mathrm{~g})$ were spiked with $100 \mu \mathrm{L}$ each of multistandard solutions of 16 PAHs $(2000 \mu \mathrm{g} /$ $\mathrm{mL})$ and 11 phenols $(100 \mu \mathrm{g} / \mathrm{mL})$. This spike level was chosen based on the concentration of old railway ties reported in previous studies. $^{2}$

Figures 1A and 1B show a representative GC-MS chromatogram of PAHs (basic) and phenols (acidic) fractions, respectively. The fractions were obtained by the proposed one step clean-up method through ion exchange liquid chromatography of the spiked wood extract. Proper integrations of the peak areas were possible for the most of the 16 PAHs due to the straight baseline and the separation of the peaks (Figure 1A). Even though a satisfactory chromatographic resolution between (1) Nap- $d_{8}$ (10.137 min) and (2) Nap (10.182 min) was not achieved, the PAHs have different ionizations and therefore their identification/quantification was possible. For the GC-MS analysis of phenols, they were derivatized by silylation reagents, i.e., BSA $(N, O$-bis(trimethylsilyl)acetamide) with 5\% TMCS (trimethylchlorosilane), to avoid broad and tailed peaks caused by the high polarity of underivatized phenols. The 9 out of 11 phenols were successfully identified as their trimethylsilyl derivatives in Figure 1B. Under the derivatization conditions, 2,4dinitrophenol and 2-methyl-4,6-dinitrophenol did not appear in the GC-MS chromatogram (Figure 1B) as previously reported. ${ }^{14}$ Therefore, the two phenolic compounds were not considered in latter studies. Figure 1B also shows a peak identified as (4) benzoic acid trimethylsilyl ester, which was a derivative of benzoic acids released from the ion exchange resin during the clean-up step.

Next, we compared the proposed one step clean-up method 
Table 1. List of PAHs and phenols covered in this study

\begin{tabular}{|c|c|c|c|c|}
\hline Peak No. & Analyte & Abbreviation & Quantitation Ion $(\mathrm{m} / \mathrm{z})$ & Comment \\
\hline \multicolumn{5}{|c|}{ PAHs } \\
\hline 1 & Naphthalene- $d_{8}$ & Nap- $d_{8}$ & 136 & I.S. \\
\hline 2 & Naphthalene & Nap & 128 & Target \\
\hline 3 & Acenaphthylene & Acy & 152 & Target \\
\hline 4 & Acenaphthylene- $d_{10}$ & Ace- $d_{10}$ & 164 & I.S. \\
\hline 5 & Acenaphthene & Ace & 154 & Target \\
\hline 6 & Fluorene & Flo & 166 & Target \\
\hline 7 & Phenanthrene- $d_{10}$ & Phe- $d_{10}$ & 188 & I.S. \\
\hline 8 & Phenanthrene & Phe & 178 & Target \\
\hline 9 & Anthracene & Ant & 178 & Target \\
\hline 10 & Fluoranthene & Flu & 202 & Target \\
\hline 11 & Pyrene & Pyr & 202 & Target \\
\hline 12 & Benzo $[a]$ anthracene & $\mathrm{BaA}$ & 228 & Target \\
\hline 13 & Chrysene- $d_{12}$ & Chry- $d_{12}$ & 240 & I.S. \\
\hline 14 & Chrysene & Chry & 228 & Target \\
\hline 15 & Benzo $[b]$ fluoranthene & $\mathrm{BbF}$ & 252 & Target \\
\hline 16 & Benzo $[k]$ fluoranthene & $\mathrm{BkF}$ & 252 & Target \\
\hline 17 & Benzo $[a]$ pyrene & $\mathrm{BaP}$ & 252 & Target \\
\hline 18 & Perylene- $d_{12}$ & Per- $d_{12}$ & 264 & I.S. \\
\hline 19 & Indeno $[1,2,3-c, d]$ pyrene & Inp & 276 & Target \\
\hline 20 & Dibenzo $[a, h]$ anthracene & $\mathrm{DbA}$ & 278 & Target \\
\hline 21 & Benzo $[g, h, i]$ perylene & $\mathrm{BgP}$ & 276 & Target \\
\hline \multicolumn{5}{|c|}{ Phenols } \\
\hline 1 & Phenol-TMS & Ph-TMS & 151 & Target \\
\hline 2 & 2-Chlorophenol-TMS & 2CP-TMS & 185 & Target \\
\hline 3 & 2,4-Dimethylphenol-TMS & 24DMP-TMS & 179 & Target \\
\hline 5 & 4-Chloro-3-methylphenol-TMS & 4C3MP-TMS & 199 & Target \\
\hline 6 & 2,4-Dichlorophenol-TMS & 24DCP-TMS & 219 & Target \\
\hline 7 & 2-Nitrophenol-TMS & 2NP-TMS & 196 & Target \\
\hline 8 & 2,4,6-Trichlorophenol-TMS & 246TCP-TMS & 253 & Target \\
\hline 9 & 4-Nitrophenol-TMS & 4NP-TMS & 196 & Target \\
\hline 10 & Anthracene- $d_{10}$ & Ant- $d_{10}$ & 188 & I.S. \\
\hline 11 & Pentachlorophenol-TMS & PCP-TMS & 323 & Target \\
\hline
\end{tabular}

I.S. $=$ Internal Standard

(A)

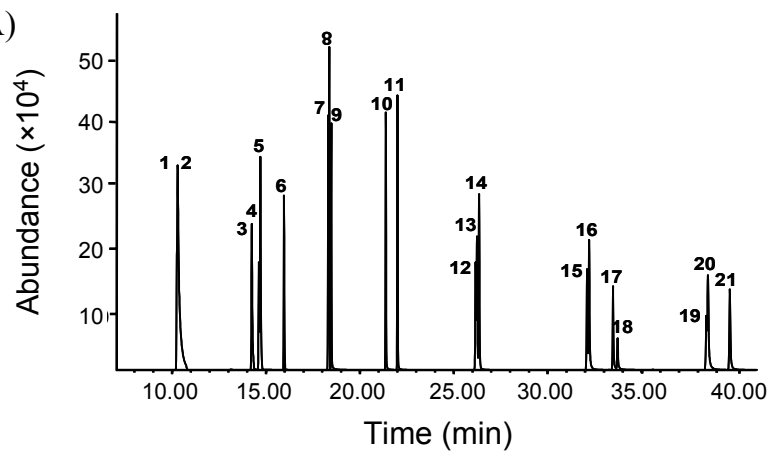

(B)

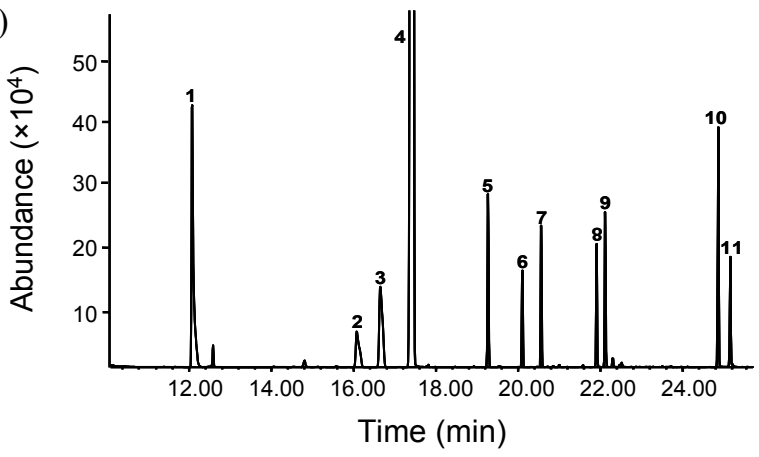

Figure 1. GC-MS chromatograms of (A) PAHs and (B) phenols fractions obtained from spiked noncreosote-treated wood extract. utilizing ion exchange resins with a conventional acid/base partition clean-up method, i.e. EPA method 3650, in terms of recovery. Figures $2 \mathrm{~A}$ and $2 \mathrm{~B}$ compare the recovery levels of the clean-up methods for 16 PAHs and 9 phenols, respectively, on spiked $0.5 \mathrm{~g}$ noncreosote-treated wood samples $(\mathrm{n}=5)$. The recoveries of PAHs by the proposed ion-exchange resin approach ranged from $93.8 \%$ for Nap to $97.9 \%$ for Ant, while the ones by the acid/base partition method varied from $88.8 \%$ for Nap to $97.0 \%$ for Chry (Figure 2A). The use of ion exchange resin also provided higher recoveries of phenols ranging from $72.0 \%$ for $\mathrm{Ph}$ to $93.8 \%$ for $\mathrm{PCP}$ than ones obtained using the acid/base partitioning method (Figure 2B). The lower recoveries obtained by the acid/base partition can be attributed to loss of the analytes in emulsions which were difficult to avoid during the partitioning process. Figure 2 also indicates that the recoveries of phenols were lower than ones of PAHs in both of clean-up methods, which can be explained by high volatility of phenols compared to PAHs.

The present ion exchange resin method was validated further in terms of method detection limit (MDL) (Table 2). The MDL was calculated as the minimum concentration of an analyte which can be reported with $99 \%$ confidence that the analyte concentration is greater than zero. The MDLs were found in the range of $1.9 \sim 4.7 \mu \mathrm{g} / \mathrm{kg}$ (PAHs) and $7.2 \sim 13.3 \mu \mathrm{g} / \mathrm{kg}$ (phenols) 
(A)

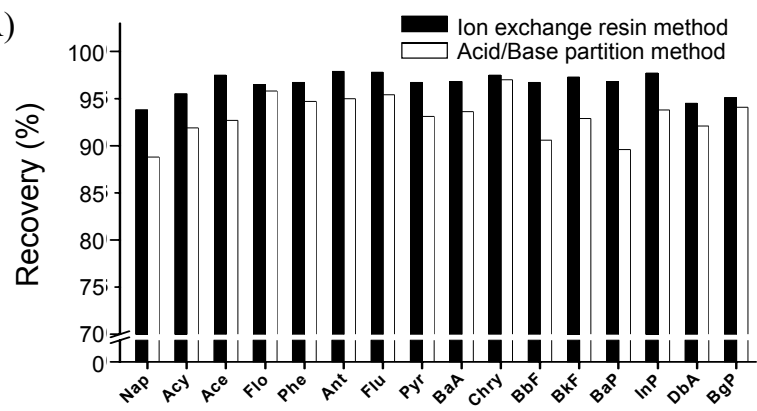

(B)

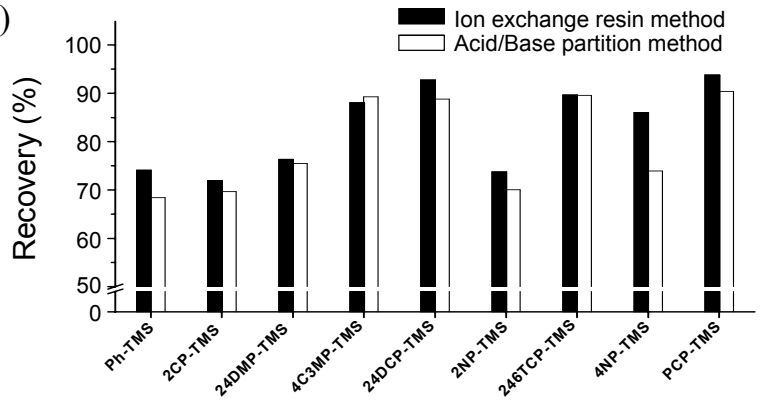

Figure 2. Recovery levels of clean-up methods for (A) PAHs and (B) phenols on spiked noncreosote-treated wood samples.

for the proposed ion exchange resin method, and $2.1 \sim 4.5 \mu \mathrm{g} /$ $\mathrm{kg}$ (PAHs) and $7.4 \sim 14.2 \mu \mathrm{g} / \mathrm{kg}$ (phenols) for the acid $/$ base partition method, respectively. The detailed result shown in Table 2 indicates that the analytical performance of the proposed method is better or, at least, comparable to that of the conventional acid/base partition method.

After validating the proposed ion exchange resin method, we applied it to evaluate the contents of PAHs and phenols in real creosote-treated wood samples and compared the analytical results with ones obtained from the acid/base partition method. The reliability of the entire analytical procedure was evaluated strictly by checking the recovery of spiked surrogates. Pyrene- $d_{10}$ and ${ }^{13} \mathrm{C}_{12}$-labelled pentachlorophenol were used as surrogate standards, i.e. compounds that are chemically similar to the analytes but not expected to be present in the samples. The recovery of surrogates were within acceptable limits of $70 \sim$ $130 \%$. As shown in Table 3, both methods, i.e. the proposed and the conventional methods, successfully detected all of 16 PAHs and quantified Ace as a major PAH compound in the creosote-treated samples. Phenolic compounds such as $\mathrm{Ph}$ and 24DMP were also detected in the creosote-treated samples with concentration ranging from 12 to $13 \mathrm{mg} / \mathrm{kg}$ (ion exchange resin method) or from 10 to $11 \mathrm{mg} / \mathrm{kg}$ (acid/base partition method) (Table 3). Those results indicate that the proposed approach provides quantitative analysis compatible to the conventional EPA method, i.e. acid/base partition method.

The present study clearly demonstrated that the proposed approach using ion exchange resin is a good alternative one step clean-up technique to conventional methods such as EPA $3650 \mathrm{acid} / \mathrm{base}$ partition for the quantitative analysis of both PAHs and phenols in creosote-treated wood. The ion exchange resin clean-up method was simpler, consumed less organic solvent, and more convenient in performing while providing analytical results which were, at least, equivalent to that of the con-
Table 2. Comparison of MDL for analysis of PAHs and phenols

\begin{tabular}{|c|c|c|}
\hline Analyte & $\begin{array}{l}\text { Ion exchange resin } \\
\text { method }(\mu \mathrm{g} / \mathrm{kg})\end{array}$ & $\begin{array}{l}\text { Acid/Base partition } \\
\text { method }(\mu \mathrm{g} / \mathrm{kg})\end{array}$ \\
\hline \multicolumn{3}{|l|}{ PAHs } \\
\hline Nap & 2.8 & 2.6 \\
\hline Acy & 2.8 & 2.4 \\
\hline Ace & 2.6 & 2.8 \\
\hline Flo & 2.7 & 2.5 \\
\hline Phe & 3.0 & 2.6 \\
\hline Ant & 2.7 & 2.6 \\
\hline Flu & 2.5 & 2.6 \\
\hline Pyr & 2.9 & 2.1 \\
\hline $\mathrm{BaA}$ & 1.9 & 2.4 \\
\hline Chry & 3.2 & 3.4 \\
\hline $\mathrm{BbF}$ & 3.3 & 3.6 \\
\hline $\mathrm{BkF}$ & 3.4 & 3.9 \\
\hline $\mathrm{BaP}$ & 3.6 & 3.5 \\
\hline $\mathrm{InP}$ & 4.5 & 4.0 \\
\hline $\mathrm{DbA}$ & 4.7 & 4.5 \\
\hline $\mathrm{BgP}$ & 4.6 & 4.5 \\
\hline \multicolumn{3}{|l|}{ Phenols } \\
\hline Ph-TMS & 13.3 & 14.2 \\
\hline 2CP-TMS & 11.6 & 10.2 \\
\hline 24DMP-TMS & 9.4 & 13.5 \\
\hline 4C3MP-TMS & 8.7 & 8.6 \\
\hline 24DCP-TMS & 8.3 & 11.9 \\
\hline 2NP-TMS & 9.7 & 10.2 \\
\hline 246TCP-TMS & 7.2 & 10.3 \\
\hline 4NP-TMS & 8.4 & 7.4 \\
\hline PCP-TMS & 10.2 & 9.7 \\
\hline
\end{tabular}

Table 3. Amounts of PAHs and phenols in creosote-treated commercial woods

\begin{tabular}{|c|c|c|}
\hline Analyte & $\begin{array}{l}\text { Ion exchange resin } \\
\text { method }(\mathrm{mg} / \mathrm{kg})\end{array}$ & $\begin{array}{l}\text { Acid/Base partition } \\
\text { method }(\mathrm{mg} / \mathrm{kg})\end{array}$ \\
\hline \multicolumn{3}{|l|}{ PAHs } \\
\hline Nap & 2348 & 2153 \\
\hline Acy & 200 & 167 \\
\hline Ace & 11752 & 10467 \\
\hline Flo & 6905 & 6220 \\
\hline Phe & 8680 & 9071 \\
\hline Ant & 3295 & 2671 \\
\hline Flu & 5129 & 4605 \\
\hline Pyr & 3176 & 2990 \\
\hline $\mathrm{BaA}$ & 1282 & 1096 \\
\hline Chry & 888 & 897 \\
\hline $\mathrm{BbF}$ & 525 & 469 \\
\hline $\mathrm{BkF}$ & 506 & 407 \\
\hline $\mathrm{BaP}$ & 462 & 451 \\
\hline InP & 132 & 167 \\
\hline $\mathrm{DbA}$ & 45 & 50 \\
\hline $\mathrm{BgP}$ & 103 & 118 \\
\hline \multicolumn{3}{|l|}{ Phenols } \\
\hline Ph-TMS & 13 & 12 \\
\hline 2CP-TMS & ND & ND \\
\hline 24DMP-TMS & 10 & 11 \\
\hline 4C3MP-TMS & ND & ND \\
\hline 24DCP-TMS & ND & ND \\
\hline 2NP-TMS & ND & ND \\
\hline 246TCP-TMS & ND & ND \\
\hline 4NP-TMS & ND & ND \\
\hline PCP-TMS & ND & ND \\
\hline
\end{tabular}

$\mathrm{ND}=$ below $\mathrm{MDL}$ 
ventional method. It is easily envisioned that the proposed method can be applied to screening of creosote-contaminated wood or environmental matrix samples.

\section{Experimental Section}

Chemicals and materials. A standard solution of 16 PAHs $(2000 \mu \mathrm{g} / \mathrm{mL}$ each in benzene/dichloromethane) and an internal standard of 5 deuterated PAHs $(2000 \mu \mathrm{g} / \mathrm{mL}$ each in dichloromethane) were purchased from Supelco (USA) (Table 1). A standard mixture of 11 phenols $(2000 \mu \mathrm{g} / \mathrm{mL}$ each in dichloromethane $)$ and an internal standard Ant $-d_{10}(200 \mu \mathrm{g} / \mathrm{mL}$ in acetone) were obtained from AccuStandard (USA) (Table 1). Surrogate standards, i.e. Pyrene- $d_{10}\left(\operatorname{Pyr}-d_{10}\right)$ and ${ }^{13} \mathrm{C}_{12}$-Labeled pentachlorophenol, were obtained from AccuStandard (USA) and Sigma (USA), respectively. Pesticide-grade dichloromethane and hexane were purchased from Wako (Japan). Anhydrous sodium sulfate, formic acid, and diethyl ether were used as received from Kanto (Japan). BSA with 5\% TMCS as derivatization reagents was supplied by Fluka (USA). New creosote-treated and noncreosote-treated woods were purchased from Dong-yang Lumber Co. (Korea).

Accelerated solvent extraction (ASE). The noncreosote-treated woods were washed with distilled water and dried at room temperature. Wood samples were obtained by drilling three sections approximately $2 \mathrm{~cm}$ in depth from the wood surface. The samples $(0.5 \mathrm{~g})$ were subjected to extraction using an ASE200 system (Dionex Corporation, Sunnyvale, CA) after mixing with diatomaceous earth which was used to fill up the dead volume of extraction cells $(11 \mathrm{~mL})$ under the following conditions: heat time $5 \mathrm{~min}$, static time $10 \mathrm{~min}$, temperature $100{ }^{\circ} \mathrm{C}$, pressure 1500 bars, purge $60 \mathrm{~s}$, and dichloromethane used as solvent.

Ion exchange resin fractionation. After ASE extraction, the extracts were concentrated to approximately $1 \mathrm{~mL}$ under $\mathrm{N}_{2}$ flow at room temperature. The concentrated extracts were loaded at the top of a Sep-Pak cartridge packed with $500 \mathrm{mg}$ of ion exchange resins (Part No. 730378, MACHEREY-NAGEL GmbH \& Co., Germany). The PAHs (basic/neutral fraction) were eluted with $20 \mathrm{~mL}$ of hexane and $5 \mathrm{~mL}$ of a mixture of hexane/dichloromethane $(3: 1, v / v)$. The final volume was adjusted to $100 \mathrm{~mL}$ with hexane. The phenols (acidic fraction) was eluted with $10 \mathrm{~mL}$ of a mixture of formic acid/diethyl ether $(2 \%)$. The fraction was then dried with anhydrous sodium sulfate and its volume was reduced to $1 \mathrm{~mL}$ under a gentle steam of $\mathrm{N}_{2}$. The solvent was changed to dichloromethane and the final volume was adjusted to $5 \mathrm{~mL}$.

Acid/base partition fractionation. For comparison of the proposed method with a conventional clean-up method, the extracts were fractionated using EPA 3650 method as previously reported. ${ }^{12}$ Briefly, the extract obtained from ASE extraction was shaken with dichloromethane and dilute $\mathrm{NaOH}$ aqueous solution ( $\mathrm{pH}$ 12). PAHs (basic/neutral analytes) were primarily in the organic phase and water soluble phenols (acidic analytes) were in the aqueous phase. The organic phases containing PAHs were collected several times and concentrated under $\mathrm{N}_{2}$ flow at room temperature. The concentrated organic phase was purified using a Sep-Pak silica-cartridge (Part No. WAT036950, Waters Corp., USA) for petroleum waste. The PAHs (basic/ neutral fraction) were eluted with $20 \mathrm{~mL}$ of hexane and $5 \mathrm{~mL}$ of a mixture of hexane/dichloromethane $(3: 1, v / v)$ and its final volume was adjusted to $100 \mathrm{~mL}$ with hexane. The aqueous phases containing phenols were also collected. Its $\mathrm{pH}$ value was adjusted to $\mathrm{pH}<2$ with diluted $\mathrm{H}_{2} \mathrm{SO}_{4}$, and the phenols were extracted with dichloromethane. The collected dichloromethane phase was dried with anhydrous sodium sulfate and concentrated to the $5 \mathrm{~mL}$ under a gentle steam of $\mathrm{N}_{2}$.

GC-MS analysis. The GC-MS analyses of the PAHs and phenols fractions were carried out using an Agilent 7890A GC equipped with an Agilent 5975C network mass selective detector and an Agilent HP-5MS column $(60 \mathrm{~m} \times 0.25 \mathrm{~mm}$, $0.25 \mu \mathrm{m})$. Each (diluted) fraction was spiked with the internal standards and the sample solution $(1 \mu \mathrm{L})$ was injected into the GC-MS system in split-less mode. The oven temperature programs for the GC-MS analyses of PAHs and phenols were as follows: $100{ }^{\circ} \mathrm{C}(2 \mathrm{~min}), 10{ }^{\circ} \mathrm{C} / \mathrm{min}$ to $280{ }^{\circ} \mathrm{C}(5 \mathrm{~min}), 20{ }^{\circ} \mathrm{C} /$ min to $320^{\circ} \mathrm{C}(15 \mathrm{~min})$ for PAHs and $55^{\circ} \mathrm{C}(2 \mathrm{~min}), 40{ }^{\circ} \mathrm{C} / \mathrm{min}$ to $100{ }^{\circ} \mathrm{C}(5 \mathrm{~min}), 10{ }^{\circ} \mathrm{C} / \mathrm{min}$ to $140{ }^{\circ} \mathrm{C}(5 \mathrm{~min}), 20{ }^{\circ} \mathrm{C} / \mathrm{min}$ to $320{ }^{\circ} \mathrm{C}$ (5 min) for phenols. The carrier gas was helium, and column flows were maintained at $0.8 \mathrm{~mL} / \mathrm{min}$ for PAHs and $1.0 \mathrm{~mL} / \mathrm{min}$ for phenols, respectively. The injection temperature was $300{ }^{\circ} \mathrm{C}$. The GC-MS transfer line temperature was maintained at $280{ }^{\circ} \mathrm{C}$ and the ion source temperature was $250{ }^{\circ} \mathrm{C}$. Detection was carried out using selected ion monitoring (SIM). Before the GC-MS analysis of phenols fractions, $100 \mu \mathrm{L}$ of BSA with $5 \%$ TMCS was mixed with $500 \mu \mathrm{L}$ of the phenols fraction with appropriate amount of the internal standard Ant- $d_{10}$ in a $\mathrm{GC}$ vial for derivatization of the phenols. The mixture in the sealed vial was kept at $60{ }^{\circ} \mathrm{C}$ for $10 \mathrm{~min}$.

Acknowledgments. This work was supported by a grant from the Kyung Hee University in 2010 (20100694).

\section{References}

1. In Concise International Chemical Assessment Document 62; World Health Organization: Geneva, 2004; Vol. 62, p 4.

2. Moret, S.; Purcaro, G.; Conte L. S. Science of the Total Environment 2007, 386, 1 .

3. In Volume 32 Polynuclear Aromatic Compounds, Part 1, Chemical, Environmental and Experimental Data; World Health Organization: Lyon, France, 1983.

4. Jones, K. C.; Voogt, P. D. Environmental Pollution 1999, 100, 209.

5. Chiang, K. C.; Liao, C. M. Science of the Total Environment 2006, 372,64

6. James, M.; Peter, C.; Pritchard, P. Environmental Science and Technology 1989, 23, 1997.

7. U.S. Environmental Protection Agency; Carcinogen Assessment Group, Washington, D.C., 1985.

8. U.S. Environmental Protection Agency; Washington, D.C., 1979.

9. Veningerová, M.; Prachar, V.; Uhnák, J.; Lukicsovi, M.; Tmovec, T. Journal of Chromatography B 1994, 657, 103.

10. Jorens, P. G.; Schepens, P. J. C. Human \& Experimental Toxicology 1993, 12, 479.

11. Ikarashi, Y.; Kaniwa, M.; Tsuchiya, T. Chemosphere 2005, 60, 1279.

12. Leslie, C.; Rola, B.; Robert, B.; William, R.; Lingyu, H.; Thomas, M.; Kirby, C. D. Journal of Toxicology and Environmental Health, Part A 2003, 66, 1351.

13. U.S Environmental Protection Agency; Register, F., Ed.: Washington, 1987.

14. Saraji, M.; Bakhshi, M. Journal of Chromatography A 2005, 1098, 30. 